\title{
Current state of existing project risk modeling and analysis methods with focus on fuzzy risk assessment - Literature Review
}

\author{
Pejman Rezakhani \\ Kyungpook. National University, School of Civil and Architectural Engineering, \\ 1370 Sankyuk-dong, Buk-gu, Daegu 702-701, Korea \\ rezakhani@knu.ac.kr
}

\begin{abstract}
Risk modeling and analysis is one of the most important stages in project success. There are many approaches for risk assessment and an investigation of existing methods helps in developing new models . This paper is an extensive literature survey in risk modeling and analysis methods with main focus on fuzzy risk assessment.
\end{abstract}

KEYwORDS. Risk modelling; Fuzzy risk assessment; Project risk.

\footnotetext{
A risk is defined as the potential for complications and problems with respect to the completion of a project and the achievement of a project goal [1] and as an uncertain future event or condition with the occurrence rate of greater than $0 \%$ but less than $100 \%$ that has an effect on at least one of project objectives (i.e., scope, schedule, cost, or quality, etc). In addition, the impact or consequences of this future event must be unexpected or unplanned [2]. It is well accepted that risk can be effectively managed to mitigate its' adverse impacts on project objectives, even if it is inevitable in all project undertakings. The source of risk includes inherent uncertainties and issues relative to company's fluctuating profit margin, competitive bidding process, weather change, job- site productivity, the political situations, inflation, contractual rights, and market competition, etc [3]. It is important for the construction companies to face these uncertain risks by assessing their effects on the project objectives because a risk quantitative method allows deciding which of the project is more risky, planning for the potential sources of risk in each project, and managing each source during construction [4]. It is noteworthy that risk is distinguished from uncertainty. The one is measurable uncertainty; the other is immeasurable risk $[3,5,6]$.

Therefore, managing risks is involved in identifying, assessing and prioritizing risks by monitoring, controlling, and applying managerial resources with a coordinated and economical effort so as to minimize the probability and/or impact of unfortunate events and so as to maximize the realization of project objectives [7]. Project risk management, which has been practiced since the mid-1980s, is one of the nine main knowledge areas of the project management institute's project management body of knowledge [8]. Effective risk management may lead the project manager to several benefits such as identification of favorable alternative course of action, increased confidence in achieving project objective, improved chances of success, reduced surprises, more precise estimates (through reduced uncertainty), reduced duplication of effort (through team awareness of risk control actions), etc [9].

Systemic project risk management has an effect on the project success. It is found that there is a strong relationship between the amount of risk management efforts undertaken in a project and the level of the project success [10]. Several project risk management approaches are proposed as follows; i.e., PRAM [11], RAMP [12], PMBOK [13], RMS [14], etc [15]. Existing approaches may be summarized into a four phase process for effective project risk management, i.e., Identifying risks, assessing risks, responding risks, and monitoring and/or reviewing risks. Identifying risks is the first step which determines which risk components may adversely affect which project objectives and documents their characteristics [3]. Construction risks are classified in many ways by risk types (i.e., natures, and magnitudes, etc), the sources and/or origins, or project phase [16-19]. Some of the existing researchers propose a hierarchical structure of risks which classifies the risks according to their origin and the location which the risk impacts to the project [20, 21].
} 
Assessing risks is the step which prioritizes the risks for further analysis by quantifying their occurrence rates. Risk assessment method is an essential component for this step. The existing methods are classified into (1) simple classical methods, and (2) advanced mathematical models [3]. The existing risk assessment methods are either qualitative or quantitative which require different information and the level of detail [22]. The simple classical methods integrate deterministic risk modeling and analysis into CPM scheduling. The deterministic methods include sensitivity analysis [23], critical path method [24], fault tree analysis [25], event tree analysis [26], failure mode, and effects and criticality analysis, etc [27]. Other advanced approaches were proposed as follows; a Monte Carlo Simulation [23] for stochastic quantitative modeling and analysis; scenario analysis [28], and fuzzy set theory for qualitative judgment [28]. There are many factors which should be considered when a project risk manager selects a risk assessment method as follows; i.e., the cost of employing the technique, the level of external party`s approval, organizational structure, agreement, adoptability, complexity, completeness, level of risk, organizational size, organizational security philosophy, consistency, usability, feasibility, validity, and credibility and automation [29]. It is essential for the risk manager to have high quality data in order to effectively apply the quantitative methods, even if it is not easy to obtain such high quality data relative to risk items in the construction industry. The difficulty is attributed to address the uncertainties and subjectivities associated with construction activities [30]. Beside the lack of collectability, the uniqueness, and non-repetitive nature of construction projects impedes using probabilistic risk quantification approaches [31].

Responding risks is involved in developing options and/or actions to enhance opportunities to achieve the project objectives. Finally, monitoring and reviewing risks is to implement a risk response plan, to keep tracking of the risks identified, to monitor residual risks, to identify new risks, and to evaluates the effectiveness of the project risk management process [15]. For this step, each engineering expertise should use specialized risk management tool as shown in Table 1 for risk analysis depending on project phase.

\begin{tabular}{|c|c|c|c|c|}
\hline Discipline & $\begin{array}{c}\text { Planning/ } \\
\text { Programming }\end{array}$ & $\begin{array}{l}\text { Preliminary } \\
\text { Engineering }\end{array}$ & $\begin{array}{l}\text { Final } \\
\text { Design }\end{array}$ & Construction \\
\hline Planning & $\bullet$ & $\bullet$ & 0 & \\
\hline Environmental & - & - & 0 & 0 \\
\hline Funding Approval & - & - & 0 & \\
\hline Project Management & 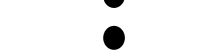 & $\bullet$ & $\bullet$ & - \\
\hline Engineering & $\bullet$ & $\bullet$ & $\bullet$ & $\bullet$ \\
\hline Civil, Structural, Systems & 0 & 0 & $\bullet$ & $\bullet$ \\
\hline Cost Estimating & 0 & 0 & $\bullet$ & $\bullet$ \\
\hline Scheduling & 0 & $\bullet$ & $\bullet$ & $\bullet$ \\
\hline Budgeting Controls & 0 & 0 & $\bullet$ & 0 \\
\hline Real Estate/Right of Way & 0 & - & - & 0 \\
\hline Construction Management/Oversight & 0 & 0 & $\bullet$ & - \\
\hline Constructability/Contractor & O & O & 0 & - \\
\hline Other Technical (e.g. Legal, Permitting, Procurement) & O & $\bullet$ & $\bullet$ & - \\
\hline Risk Facilitation & 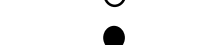 & 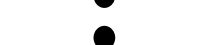 & 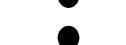 & 0 \\
\hline
\end{tabular}

Table 1: Key expertise for risk analysis by project phase (Adapted from [32]). - Highly desirable; O Desirable but optional depending upon circumstances.

\section{FUZZY RISK AssESSMENT}

A

fter Zadeh [33] introduced the concept of Fuzzy sets, and Fuzzy set theory, several researchers such as Kangari [34], Kangari and Riggs [35], Peak et al. [36], Tah and McCaffer [20], Wirba et al. [21], , Cho et al. [38], Choi et al. [39], Lyons and Skitmore [40], Baker and Zeng [41], Dikmen et al. [42], Zeng et al. [30], Wang and Elang [43], Karimiazar et al. [3], and Nieto et al. [15] -introduced fuzzy set theory(FST)-based risk modeling and analysis methods that deal with ill-defined, vague, imprecise, and complex risk analysis problems. For example, Kangari [34] proposes the application of fuzzy theory in risk analysis method using linguistic terms. The fuzzy theory-based risk analysis method was implemented as a part of construction project risk management system which consists of five steps (i.e., risk identification, policy definition, risk sharing and allocation, risk analysis, and risk minimization and response planning, etc). The fourth component, risk analysis, consists of three steps as follows; natural language computation, fuzzy set risk evaluation, and linguistic approximation. 
Kangari and Riggs [35] presents a risk analysis model, which makes use of Fuzzy set theory (FST) as a risk assessment tools, consists of three modess follows; natural language computation, fuzzy set evaluation of risk, and linguistic approximation [44]. Specifically, the linguistic approximation method handle subjectivity issues in construction risk assessment by finding the nearest natural language expression for the estimated fuzziest using Euclidean distance in order to. Peak et al. [36] propose a risk pricing model that en determines the bid price of a construction project. The model estimates the risk-associated consequence as fuzzy numbers that represent risk consequences to reflect the uncertainty involved in determining the bid price. The fuzzy numbers are assumed by two intervals; i.e., the most likely and the largest likely intervals which are obtained from either historical data or expert opinions. The model applies fuzzy arithmetic operation to compute the risk contingency value and . a ranking method to calculate the value of risk contingency in terms of monetary cost by transferring the fuzzy number into crisp value. The method was verified by applying it to a real construction project. Tah and McCaffer [20] introduced a computer tool which approximates the amount of contingency cost in PASCAL programming. The system determines the risk level in linguistic terms to be used as the basis of the contingency allocation for tender preparation. . It proposes a new risk breakdown structure called a hierarchical riskbreakdown structure (HRBS) which presents contractor's risk. Wirba et al. [21] presented a fuzzy set theory-based risk assessment approach which identifies risks, checks for dependencies amongst them, and assesses risk likelihood of occurrence by using linguistic variables. Carr and Tah [37] presented a fuzzy set based qualitative risk assessment model which implements hierarchical risk breakdown structure. The model allows to define the risk descriptions and their consequences using linguistic variables and to formulate the rules using the relationship between the likelihood of occurrence (L), the severity (V), and the effect of risk factor (E), i.e., "If L and V then E". Fuzzy approximation and composition were performed to identify and quantify the relationship between risk sources and the consequences on project performance measures. It evaluates the risk exposure by assessing the consequences relative to project performance measures (i.e., time, cost, quality and safety, etc) using the fuzzy estimates of the risk components. Cho, et al. [38] proposed an uncertainty range estimate method which incorporates uncertainties using fuzzy concepts. The method introduces some forms of fuzzy membership functions that that represents the degree of uncertainties involved in both probabilistic parameter estimates and subjective judgments. The method uses linguistic variables (i.e., "close to any value" or "Higher/Lower than analyzed value", etc) which include some quantification with giving specific value by defining three membership functions(i.e., "Close to", "Lower than", and "Higher than" curves). Choi, et al. [39] presented a fuzzybased uncertainty assessment system which considers uncertainty as objective probabilities and subjective judgment by incorporating probabilistic or linguistic variables. The system was under rigorous tests with underground construction. It implements four steps, i.e., identifying, analyzing, evaluating and managing the risks inherent in construction projects. It was confirmed that the system accommodate both probabilistic data obtained from historical data and subjective data obtained from expert group. An et al. [44] proposed risk assessment or risk management system for construction project. This system has also proposed a risk analysis method as a part of the risk management system developed. Dikmen et al. [42] propose a fuzzy risk rating method which rates the risk involved in cost overrun in international construction projects. The model introduces "Controllability" or "Manageability" concepts into the contractor's decision making which determines if the contractor enters into international market. It allows assessing the contractor's decision using four categories, i.e., internationalization, market selection, project selection, and markup selection. The system identifies risks, models the risks using influence diagrams, selects membership function of each variable, captures the experts' opinion using aggregation rules, aggregates fuzzy rules into a fuzzy cost overrun risk rating, carries out fuzzy operations, and determine the risk level of an international project by quantifying the final risk rating. Zeng et al. [30] hybridized fuzzy reasoning and AHP approach to to handle subjective assessments and to prioritize diverse risk factors, respectively [44]. The model quantifies the risk magnitude (RM) of risks a by integrating a risk parameter called factor index (FI) which evaluate the magnitude of possible risk and combine it with risk likelihood (RL) and risk severity (RS) into the fuzzy inference system. The system utilized a modified fuzzy AHP to capture and convert expert's fuzzy information and subjective judgment. Wang and Elang [46] proposed a fuzzy multi criteria and multi participant decision making approach which allows decision makers to rapidly and effectively evaluate multiple fuzzy risk factors using linguistic terms by aggregating the assessments of multiple risk factors. Zhang and Zou [45] proposed a methodology which produces the appraisal vector of risky conditions of the construction project by aggregating the weight coefficient of risk groups, and fuzzy risk factors obtained from experts using the AP technique, a hierarchical structure of risks, and the fuzzy evaluation matrixes of risk factors. Nieto et al. [15] proposed an algorithm to handle the inconsistency in the fuzzy preference relation when pair-wise comparison judgments are necessary. Karimiazari et al. [3] proposed an extended version of Technique for Order Preference by Similarity to Ideal Solution (TOPSIS) which solve the multi criteria risk assessment model under a fuzzy environment. Lyons and Skitmore [40] describes the common procedure that all fuzzy risk assessment methods retain as follows; The first step, Definition and measurement of parameters, is to define the risk 
probability and the risk severity with which a project are assessed. in linguistic terms and to convert them into corresponding fuzzy numbers. Second step, Definition of fuzzy inference, is to define the relations between input parameters and output parameters in "if-then" rules or mathematical functions using an appropriate fuzzy arithmetic operator. Final step, Defuzzification, is to convert the fuzzy result into an exact numerical value.

These and other researchers recommend taking into account the imprecise, vagueness, and fuzziness of the risk factors in a construction project to appropriately deal with a contractor's project risks by using Fuzzy Set Theory (FST). It is well accepted that Fuzzy Set Theory (FST) provides a useful way to deal with ill-defined and complex problems in a decision making by quantifying imprecise information, incorporating vagueness, and making decisions based on the imprecise and vague data. The method allows translating the subjective judgment given in linguistic expressions (i.e., "low", "high" etc) into mathematical measures. Dikmen et al. [42] mentions that FST is commendable to project-based industries because it is almost impossible to use probabilistic methods due to the unique nature of construction undertakings. The rational to use FST in project risk assessment are as follows; first, the modeling of vague input is successfully done with the use of membership functions. Second, the inherent ability of FST to explain its reasoning ensures that the modeling process is understood and could also be intuitively verified. Third, the parallel nature in which rules are activated in a fuzzy system ensures that all factors are considered in a harmonized manner. Fourth, the results of fuzzy systems can naturally be scaled to be comparable with each other, with the use of the scaling membership functions. Finally, Fuzzy logic's use of linguistic sets and rules ensures that the terminology of the user interface and modeling structure can be tailored toward the specific environments.

\section{REFERENCES}

[1] W. Mark, P. E. Cohen, R. P. Glen, Project Risk Identification and Management. AACE International Transaction. INT.01.1-5.S (2004).

[2] E. Chia, Risk assessment framework for project management. IEEE, (2006) 376.

[3] Karimiazari et al., Expert Systems with Applications, 38 (2011) 9105.

[4] T. Zayed, M. Amer, J. Pan, International Journal of Project Management, 26 (4) (2008) 408.

[5] D. Hillson, Effective opportunity management for projects - exploiting positive risk. New York: Marcel Dekker (2004)

[6] R. Olsson, International Journal of Project Management, 25 (2007) 745.

[7] H. Douglas,. The failure of risk management: Why it's broken and how to fix it. John Wiley and sons, (2009) 46.

[8] Tuysuz, Kahreman, International Journal of Intelligent Systems, 21 (2006) 559.

[9] P. L. Bannerman, The Journal of Systems and Software, 81(12) (2008) 2118.

[10] P. Elkington, C. Smallman, International Journal of Project Management, 20 (2002) 49.

[11] C. Chapman, International Journal of Project Management, 15 (1997) 273.

[12] Risk Analysis and Management for Projects (RAMP). Institution of Civil Engineers and Faculty and Institute of Actuaries. Thomas Telford, London (2002).

[13] Project Management Institute,. A guide to the project management body of knowledge. Project Management Institute Standards Committee (2008).

[14] Institute of Risk Management,. A risk management. Standard Institute of Risk Management (2002).

[15] A. Nieto-Morote, F. Ruz-Vila, International Journal of Project Management, 29 (2011) 220.

[16] D. F. Cooper, C. B. Champan, Risk Analysis for Large Project.Wiley, Chichester (1987).

[17] P. J. Edwards, P. A. Bowen, Engineering, Construction and Architectural Management, 5(4) (1998) 339.

[18] A. Klemetti, Risk management in construction project networks. Report 2006/ 2. Finland: Laboratory of Industrial Management, Helsinki University of Technology (2006).

[19] L. Zhou, A. Vasconcelos, M. Numes, Information Management \& Computer Security, 16 (2008) 166.

[20] J. H. M. Tah, A. Thorpe, R. McCaffer, Computing System in Engineering, 4 (1993) 281.

[21] E. N. Wirba, J. H. M.Tah, R. Howes, Journal of Engineering, Construction and Architectural Management, 3 (1996) 251.

[22] J. C. Bennett, G. A. Bohoris, E. M. Aspinwall, R.C. Hall, European journal of operation research, 95 (1996) 467.

[23] D. White, Management Decision, 3(10) (1995) 35.

[24] A. Kaufmann, M. M. Gupta, Fuzzy mathematical models in engineering and management science. Amsterdam: North-Holland (1988).

[25] T. Terano, K. Asai, M. Sugeno, Fuzzy systems theory and its applications. San Diego, CA: Academic Press (1992). 
[26] D. Huang, T. Chen, M. -J. Wang, Fuzzy Sets and Systems, 118 (2001) 153.

[27] J. B. Bowles, C. E. Pelaez, Reliability Engineering and System Safety, 50, (1995) 203.

[28] R. K. J. R. Rainer, C. A. Snyder, H. H. Carr, Journal of Management Information Systems, 8 (1) (1991) 129.

[29] Sh. Lichtenstein, Information Management and Computer Security, 4 (1996) 20.

[30] J. Zeng, M. An, N. J. Smith, International Journal of Project Management, 25, (2007) 589.

[31] D. Baloi, A. D. F. Price, International Journal of Project Management, 21, (2003) 261.

[32] NCHRP 8-60: Guidebook on Risk Analysis Tools and Management, (2009).

[33] L. A. Zadeh, Information Control, 8 (1965) 338.

[34] R. Kangari, Civil Engineering System, 5 (1988).

[35] R. Kangari, L. S. Riggs, IEEE Transaction on Engineering Management, 36(2) (1989) 126.

[36] J. H. Paek, Y. W. Lee, J. H. Ock, Journal of Construction Engineering and Management, 119(4) (1993) 743.

[37] V. Carr, J. H. M. Tah, Advances in Engineering Software, 32 (2001), 847-857.

[38] H. N. Cho, H. H. Choi, Y. B. Kim, Reliability Engineering and System Safety, 78 (2002) 173.

[39] H. Choi, H. Cho, J. W. Seo, Journal of Construction Engineering and Management, 130(2) (2004) 258.

[40] T. Lyons, M. Skitmore, International Journal of Project Management, 22 (2004) 51.

[41] M. An, C. Baker, J. Zeng, World Journal of Engineering, 2 (2005) 1.

[42] I. Dikmen, M. Birgonul, S. Han, International Journal of Project Management, 25 (2007) 494.

[43] Y. M. Wang, T.M.-S. Elhag, Computers and Industrial Engineering, 53 (2007) 137.

[44] A. Taroun, J. B. Yang, D. Lowe, The Built and Human Environment Review, 4(1) (2011).

[45] G. Zhang, P. X. W. Zou, Journal of Construction Engineering and Management, 133 (2007) 771. 